\title{
Factors Affecting Level of Adherence Among People Living with HIV Attending Antiretroviral Care at Nnamdi Azikiwe University Teaching Hospital, Nnewi, Anambra State
}

\author{
Mary Nnenna Ibezim ${ }^{1}$, Uchechukwu Chibuzo Ogbodo ${ }^{2,}$, , John Ndie ${ }^{1}$, Ogonnaya Kanu-Oji ${ }^{3}$, \\ Ndubuisi $\mathrm{Oji}^{4}$, Michael Olugbamila Dada ${ }^{5}$, Emeka Victor Ifemenam ${ }^{6}$ \\ ${ }^{1}$ Department of Nursing Sciences, National Open University of Nigeria, Enugu Study Center, Enugu, Enugu State, Nigeria \\ ${ }^{2}$ Department of Applied Biochemistry, Nnamdi Azikiwe University, Awka, Anambra State, Nigeria \\ ${ }^{3}$ Department of Medicine and Surgery, Abia State University, Uturu, Abia State, Nigeria \\ ${ }^{4}$ Institute of Development Studies, University of Nigeria, Enugu Campus, Enugu, Enugu State, Nigeria \\ ${ }^{5}$ Department of Public Health, Texila American University, Georgetown, Guyana, USA \\ ${ }^{6}$ Department of Mechanical Engineering, Nnamdi Azikiwe University, Awka, Anambra State, Nigeria
}

Email address:

uc.ogbodo@unizik.edu.ng (U. C. Ogbodo)

${ }^{*}$ Corresponding author

\section{To cite this article:}

Mary Nnenna Ibezim, Uchechukwu Chibuzo Ogbodo, John Ndie, Ogonnaya Kanu-Oji, Ndubuisi Oji, Michael Olugbamila Dada, Emeka Victor Ifemenam. Factors Affecting Level of Adherence Among People Living with HIV Attending Antiretroviral Care at Nnamdi Azikiwe University Teaching Hospital, Nnewi, Anambra State. Central African Journal of Public Health. Vol. 6, No. 2, 2020 , pp. 80-87.

doi: 10.11648/j.cajph.20200602.15

Received: January 26, 2020; Accepted: February 10, 2020; Published: February 21, 2020

\begin{abstract}
The effectiveness of Antiretroviral Therapy (ART) portends a viable remedy for Human Immunodeficiency Virus (HIV) infection with some context-specific factors identified to pose barriers to adherence to treatment. Consequently, nonadherence to treatment regimens impacts on desired improved health outcomes of affected individuals and socio-economic status of the nation. This study was thus conducted to elicit specific factors that may be responsible for the poor health outcomes attributed to non-adherence among people living with HIV recorded in the study area. A cross-sectional study was conducted on people living with Human Immunodeficiency Virus (HIV) and attending ART clinic at Nnamdi Azikiwe University Teaching Hospital Nnewi from February to August 2016. Adherence was defined as taking 95\% of the prescribed doses in the week before the survey. Data collected using a standard interview questionnaire were analyzed on SPSS Version 21. Among the 272 study participants, the magnitude of adherence to ART in the week before interview was found to be $85 \%$. The main reasons for nonadherence were forgetfulness (32\%), being away from home (29\%), and being busy doing other things (14\%). Age and monthly income appeared to influence treatment adherence of clients sampled in the study. The researcher recommends a more inclusive approach to HIV care and treatment for a stronger adherence to treatment and implicates care-givers especially nurses at the center of the drive for higher adherence rates in Nigeria. A qualitative approach to the study is also recommended.
\end{abstract}

Keywords: Adherence, Antiretroviral Therapy, Human Immunodeficiency Virus, People Living with HIV

\section{Background}

The Human Immunodeficiency Virus (HIV) pandemic continues to spread across populations making HIV infection one of the most important public health crises in the world [1]. Globally, about 33.3 million persons were estimated to be infected with HIV/AIDS in 2010, of these, 22.5 million $(68 \%)$ are in sub Saharan Africa and about 3 million alone in Nigeria. This makes it the country with the second highest burden of HIV and AIDS in the world after South Africa [1]. The current prevalence rate of HIV in Nigeria as at 2010 based on the sentinel surveillance is $4.1 \%$. Anambra State is 
currently ranked the $4^{\text {th }}$ in the country with a prevalence burden of $8.7 \%$ as at 2010 [2] and is found in the South-East geopolitical zone of Nigeria [3]. In the absence of a cure, antiretroviral therapy (ART) has remained the only available option that offers the possibility of dramatically reducing HIV/AIDS-related morbidity and mortality, while improving the status of PLHIV. It has proved effective in reducing viral load, improving immune function and improving the quality of life of PLHIV [4]. However, successful long-term treatment of HIV requires strict adherence to the Highly Active Antiretroviral Therapy (HAART) regimen [4, 5]. This is especially important in countries such as Nigeria where PLHIV make up $10 \%$ of the global burden of HIV/AIDS (UNAIDS, 2008) and about 1.5 million require treatment [2]. Adherence level of at least $95 \%$ and above has been considered appropriate to achieve therapeutic success $[6,7]$ as this maintains optimal viral suppression as demonstrated by Paterson and colleagues [7, 8]. Failure to observe sustained desired adherence threshold has been associated with dire consequences such as treatment failure, disease progression and emergence of drug resistant HIV/AIDS strains [9]. With the realization of the central role played by adherence in the success of HIV/AIDS treatment, several studies conducted in various parts of the world including reviews have reported non-adherence rates ranging from $50 \%$ to $80 \%$ in different contexts $[6,10]$.

However, in reality adherence rates are often lower than $95 \%$ [7] and rates of adherence from previous studies conducted in Nigeria have ranged from as low as $44 \%$ being adherent [11] to more than 95\% from different parts of Nigeria [12]. Most of the previous reports were carried out with fewer PLHIV being on treatment restricted access to ARV, drugs unavailability and payment for ARV medications were heavily subsidized. With widespread awareness of HIV/AIDS, expansion of treatment and prevention programs that have increased ART access to previously un-served and underserved populations in Nigeria coupled with provision of free ART services [13], there is a need for implementation of continuous monitoring and evaluation mechanisms for adherence. This is of great importance especially because the key to the success of ART programmes and prevention of treatment failures is hinged on consistently high adherence levels. Scaling up of ARVs alone will definitely not halt the spread when adherence inconsistencies are not tackled. Adherence to ART is therefore crucial for treatment success among HIV patients. High levels of adherence is a prerequisite for maintained viral suppression and lower risk of drug resistance, which in turn will prevent premature morbidity and mortality [14]. Low adherence is the second strongest determinant for disease deterioration and death after CD4 count. Non-adherence to ART is a substantial challenge in resource-constrained settings where increasing drug resistance is hard to combat using the limited treatment alternatives available [15]. A dramatic reduction in HIV related morbidity and mortality has been observed in countries where ART has been made widely available [16].

Although the measurement of ART adherence is critically important in both ART interventions and clinical research, there is no "gold standard" by which to measure adherence to medication [17]. While adherence can only be ensured by directly observed treatment, this is not practical for daily therapy which has to be taken for the whole of a patient's life. Consequently, several measures are employed to determine treatment adherence among PLHIVs which include self-reporting tools such as questionnaires and visual analogue, pill counts, pharmacy refill records and electronic drug monitoring devices. The most common approach is to elicit the information by self-report, in which participants describe their adherence over a specified time interval but then it appears that self-report methods may lead to an overestimation of medication adherence, but they are often used because they are inexpensive and feasible in a wide variety of settings [18].

It is therefore important that policy makers and programme managers address the factors responsible for non-adherence when scaling up subsidized ARV treatment in Nigeria and other parts of sub-Saharan Africa. Thus, as part of the objective of this study, the first step to solving the problem of adherence is to measure its determinants especially the demographics of the subjects assessing ART care in NAUTH as it varies from one individual to another. And if Nigeria were to meet the ambitious UNAIDS global 95-95-95 targets of $95 \%$ of individuals who know their status to be on treatment by 2030, this study would throw more light on the barriers affecting adherence in this contextual setting and help proffer scale-up strategies for achieving these goals.

\section{Materials and Methods}

\subsection{Study Design}

A non-experimental cross-sectional, quantitative and descriptive research design, using the survey approach was employed for the study.

\subsection{Study Setting and Population}

Anambra State is situated in South-East zone geopolitical zone of Nigeria with Awka as the state capital. Ethnically, Anambra state is $98 \%$ of Igbo population and 2\% LGAs. The state is bounded in the northeast by Enugu state, in the east by Enugu and Abia states, in the west by Delta while in the south and northwest by Imo and Kogi states respectively. Administratively, the state is divided into 21 Local Government Areas, 235 health districts, 330 wards and 177 communities. Anambra state has an annual growth rate of about $2.80 \%$ and the state was projected to have approximately $4,984,127$ people at the end of 2012 . It is a densely populated state with about 1,500 to 2,000 persons $/ \mathrm{km}$ [3]. There are about 1,485 health facilities in the state, $72 \%$ of which are private. Within the public sector, there are two tertiary health facilities - (one owned by federal and one owned by the state government and 31 public secondary health care facilities that are managed by the Anambra state government through the State Hospital Management Board 
of the State Ministry of Health (SMoH).

Nnamdi Azikiwe University Teaching Hospital (NAUTH) located in Nnewi was selected for this study because of presence of comprehensive HIV/AIDS care services. This facility-based cross sectional study was conducted among adult male and female HIV positive patients accessing ART at NAUTH, Anambra State and have been on ART for more than 2 years.

\subsection{Sample Size and Sampling Procedures}

The study used quantitative data collection methods for the purpose of collecting data. The study population included registered adult male and female HIV-positive individuals attending ART clinic at the site for more than 2 years. The sample size for this study was determined using an appropriate statistical formula for estimating sample size in health studies: $\mathrm{n}=\mathrm{Z} 2 \mathrm{Pq} / \mathrm{d} 2$

Where:

$n=$ the required sample size;

$Z=$ the coefficient of $Z$ statistic (the standard normal deviate at $95 \%$ confidence level obtained from the standard normal distribution table);

$P=$ prevalence rate in\%;

$q=100-\mathrm{P}$;

$d=$ the desired precision of the study or sampling error tolerated in $\%$.

Using a prevalence rate $\mathrm{P}$ of $9.2 \%$ obtained from a previous similar study in Anambra state, a confidence limit of $95 \%(\mathrm{~d}=5 \%)$, and $\mathrm{Z}$ of 1.96 , the calculated sample size, $n$ will be 272 .

\subsection{Data Collection}

Data collection commenced immediately after relevant ethical approval was obtained and ended after a two-month period from January to March 2016. All clients who consented to the interview and met the inclusion criteria were administered the questionnaire. The questionnaire which was pre-tested structured consisted of multiple response sets to elicit information bordering on clients' socio-demographic characteristics, aspects of care relating to the clinic, interpersonal relationship with service providers, knowledge and experience about HIV, adherence to ART. Three trained data collectors administered the questionnaire using face-to-face exit interviews. Completed questionnaires, carefully examined for missing values were submitted to the statistician for analysis.

\subsection{Data Analysis}

Statistical analysis was done using IBM SPSS Statistics version 21 to analyze quantitative data. Characteristics of the clients were summarized and presented using proportions, means, medians, frequency tables or crosstabulations for continuous variables and proportions for categorical variables. Chi square $\left(X^{2}\right)$ test was performed to test for statistical significance between proportions for the cross tabulated variables. Level of significance was set at $p<0.05$.

\subsection{Ethical Approval}

Ethical approval and clearance for the study was obtained from the Research Ethics Committee of the hospital. Consent to conduct the study was also obtained from the ART clinic. Individual verbal informed consent, duly documented by signature, was obtained from every study participant who agreed to participate in the study based on the study inclusion criteria of being an adult male or female over 18 years of age registered in the ART clinic and having attended clinic for more than 2 years. Strict confidentiality and anonymity practices were followed in the administration of the questionnaires for all clients both during and after data collection.

\section{Results}

Table 1. Socio-demographic characteristics of respondents.

\begin{tabular}{|c|c|c|}
\hline Characteristics & Frequency $(N=272)$ & Percent (\%) \\
\hline \multicolumn{3}{|l|}{ Age in years } \\
\hline $18-24$ & 90 & 33 \\
\hline $25-34$ & 77 & 28 \\
\hline $35-44$ & 87 & 32 \\
\hline$>=45$ & 18 & 7 \\
\hline \multicolumn{3}{|l|}{ Sex } \\
\hline Male & 113 & 42 \\
\hline Female & 159 & 58 \\
\hline \multicolumn{3}{|l|}{ Location } \\
\hline Urban & 175 & 64 \\
\hline Rural & 97 & 36 \\
\hline \multicolumn{3}{|l|}{ Religion } \\
\hline Christian & 255 & 94 \\
\hline Muslim & 13 & 5 \\
\hline Others & 4 & 1 \\
\hline \multicolumn{3}{|l|}{ Marital status } \\
\hline Married & 222 & 81.6 \\
\hline Single & 37 & 13.6 \\
\hline Divorced/separated & 11 & 4 \\
\hline Widowed & 2 & 0.8 \\
\hline \multicolumn{3}{|l|}{ Level of education } \\
\hline Primary & 61 & 22 \\
\hline Secondary & 57 & 21 \\
\hline Tertiary & 121 & 44 \\
\hline Higher degree & 33 & 12 \\
\hline \multicolumn{3}{|l|}{ Occupation } \\
\hline Government employee & 75 & 28 \\
\hline Self-employed & 50 & 18 \\
\hline Trader & 52 & 19 \\
\hline Unemployed & 28 & 10 \\
\hline Others & 67 & 25 \\
\hline \multicolumn{3}{|l|}{ Average monthly income } \\
\hline$<18,000$ & 20 & 7.3 \\
\hline$>18,000-100,000$ & 69 & 25.4 \\
\hline Above 100,000 & 175 & 64.3 \\
\hline No answer & 8 & 3 \\
\hline
\end{tabular}

The table above gives the socio-demographic characteristics of sampled respondents attending ART clinic at the select site. A total of 272 HIV infected people participated in the study with the response rate of $100 \%$. The median age of the patients was 35 . While $42 \%$ of the participants were males and $58 \%$ females, $64 \%$ were urban dwellers and $36 \%$ were rural inhabitants. $94 \%$ of study 
participants were Christians, 5\% were Muslims and 1\% was of other religion. $73(30.8 \%)$ were government employees. Slightly up to half of the participants $(44 \%)$ were educated up to tertiary level with $22 \%$ of the study participants having a basic primary education. Of the study participants, $28 \%$ were government workers, $18 \%$ were self-employed, $10 \%$ were unemployed and $25 \%$ were in other forms of occupation. On average monthly income, $64.3 \%$ of the participants earned above a hundred thousand naira $(100,000)$.

Table 2. Medication and related characteristics of adult patients on ART in NAUTH.

\begin{tabular}{|c|c|c|}
\hline Characteristics & Frequency $(N=272)$ & Percent (\%) \\
\hline \multicolumn{3}{|c|}{ Duration after knowing sero-status in weeks } \\
\hline 3-12 weeks & 130 & 48 \\
\hline 13-24 weeks & 122 & 45 \\
\hline$>24$ weeks & 20 & 7 \\
\hline \multicolumn{3}{|c|}{ Duration after ART initiation in weeks } \\
\hline $1-12$ weeks & 156 & 57 \\
\hline 13-24 weeks & 101 & 37 \\
\hline$>24$ weeks & 15 & 6 \\
\hline \multicolumn{3}{|l|}{ ARV drug used } \\
\hline TDF-3TC-EFV & 92 & 34 \\
\hline AZT-3TC-NVP & 58 & 21 \\
\hline D4T-3TC-EFV & 48 & 18 \\
\hline D4T-3TC-NVP & 42 & 15 \\
\hline Others & 32 & 12 \\
\hline \multicolumn{3}{|c|}{ Experienced side effects } \\
\hline Yes & 171 & 63 \\
\hline No & 101 & 37 \\
\hline \multicolumn{3}{|c|}{ Drugs other than ARV } \\
\hline Yes & 112 & 41 \\
\hline No & 160 & 59 \\
\hline \multicolumn{3}{|c|}{ Number of pills taken in a day } \\
\hline 2 tablets & 59 & 22 \\
\hline 3 tablets & 163 & 60 \\
\hline 4 tablets & 38 & 14 \\
\hline$>=5$ tablets & 12 & 4 \\
\hline \multicolumn{3}{|c|}{ History of opportunistic infections (OIs) } \\
\hline Yes & 51 & 19 \\
\hline No & 221 & 81 \\
\hline \multicolumn{3}{|c|}{ Doses of ART status in the last 7 days } \\
\hline Missed & 89 & 33 \\
\hline Not missed & 183 & 67 \\
\hline \multicolumn{3}{|c|}{ Number of doses missed in last 7 days } \\
\hline $1-2$ doses & 38 & 14 \\
\hline $3-4$ doses & 221 & 81 \\
\hline $5-7$ doses & 13 & 5 \\
\hline
\end{tabular}

Table 2 above shows the frequency and percentages of respondents with respect to responses on medication related factors affecting their adherence in the select site of study. The majority of the respondents, 252 (93\%), were tested for HIV before 24 weeks and among those patients who were on ART, 257 (94\%) had started ART before 24 weeks. Based on patients' record review, the respondents were on combination of ART drugs with regimen of Zidovudine (AZT), Lamivudine (3TC), Nevirapine (NVP), Efavirenz (EFV), Stavudine $(\mathrm{d} 4 \mathrm{t})$ and Tenofovir (TDF). Majority of participants 92 (34\%) were on TDF-3TC-EFV, the preferred first line regimen for ART patients according to recent WHO guidelines. Majority of the patients $163(60 \%)$ were taking 3 tablets per day while few of the respondents 12 (4\%) were taking more than or equal to 5 tablets per day.

Out of the total respondents $38(14 \%)$ missed at least two doses of ART medication because of different reasons like forgetting, being away from home, being busy and other factors like fasting, sleeping, pill burden etc. in the last 7 days prior to data collection. Of the total participants, 89 (33\%) reported missing doses of ART in the last 7 days while $183(67 \%)$ affirmed not missing doses in the past one week.

Table 3. Reasons for missing medication doses for patients attending ART at NAUTH.

\begin{tabular}{lll}
\hline Reasons for missing ART doses & $\boldsymbol{N}$ & $\mathbf{\%}$ \\
\hline Forgetfulness & 88 & 32 \\
Being away from home & 79 & 29 \\
Being extremely ill & 20 & 8 \\
Being busy & 38 & 14 \\
Ran out of drugs & 12 & 4 \\
Due to adverse drug reactions & 14 & 5 \\
Pill burden & 10 & 4 \\
Fear of stigma & 5 & 1.8 \\
Being emotionally depressed & 2 & 0.7 \\
Having no money & 4 & 1.5 \\
Total & 272 & 100 \\
\hline
\end{tabular}

From the total study participants, $183(67 \%)$ of the respondents had $93.33 \%$ adherence and 89 (33\%) of the respondents had $83.33 \%$ or less level of adherence. Overall the study participants had poor adherence (less than 95\%). The main reasons given for missing their treatment were forgetting $88(32 \%)$, being away from home $79(29 \%)$, and followed by being busy with different activities 38 (14\%).

Table 4. Factors associated with ART adherence among adult patients on ART in NAUTH Anambra State, Nigeria.

\begin{tabular}{|c|c|c|c|c|}
\hline \multirow{2}{*}{ Characteristics } & \multicolumn{4}{|l|}{ Adherence status } \\
\hline & Adhered No (\%) & Not Adhered No (\%) & COR $(95 \%$ CI) & AOR (95\% CI) \\
\hline \multicolumn{5}{|l|}{ Age in years } \\
\hline $18-24$ & 67 & 33 & $0.81(0.33-2.43)$ & $0.78(0.29-2.32)$ \\
\hline $25-34$ & 83 & 17 & $1.63(1.07-2.39)$ & $1.27(0.43-2.33)$ \\
\hline $35-44$ & 92.8 & 7.2 & $2.33(1.17-4.34)$ & $2.58(1.14-4.09)^{*}$ \\
\hline$>=45$ & 87 & 13 & 1 & 1 \\
\hline \multicolumn{5}{|l|}{ Sex } \\
\hline Male & 85.7 & 14.3 & $1.77(0.84-3.54)$ & $1.83(0.46-2.78)$ \\
\hline Female & 87.5 & 12.5 & 1 & 1 \\
\hline Marital Status & & & & \\
\hline
\end{tabular}




\begin{tabular}{|c|c|c|c|c|}
\hline \multirow{2}{*}{ Characteristics } & \multicolumn{4}{|l|}{ Adherence status } \\
\hline & Adhered No (\%) & Not Adhered No (\%) & COR $(95 \% \mathrm{CI})$ & AOR (95\% CI) \\
\hline Married & 82.3 & 17.7 & 1 & 1 \\
\hline Single & 91 & 9 & $1.49(0.51-4.35)$ & $1.5(0.69-4.37)$ \\
\hline Divorced/separated & 79 & 21 & $0.87(0.22-3.47)$ & $0.9(0.08-1.63)$ \\
\hline Widowed & 77 & 23 & $1.07(0.30-3.76)$ & $1.0(0.25-4.44)$ \\
\hline \multicolumn{5}{|l|}{ Level of Education } \\
\hline Primary & 81 & 19 & $1.58(0.64-3.87)$ & $1.60(0.64-3.87)$ \\
\hline Secondary & 80 & 20 & $1.40(0.15-12.8)$ & $1.39(0.15-12.8)$ \\
\hline Tertiary & 90.7 & 9.3 & $2.44(0.77-7.72)$ & $2.4(0.77-7.72)$ \\
\hline Higher degree & 90.7 & 9.3 & 1 & 1 \\
\hline \multicolumn{5}{|c|}{ Average income/month } \\
\hline$<18,000$ & 88.3 & 11.7 & 1 & 1 \\
\hline$>18,000-100,000$ & 97.6 & 2.4 & $4.13(1.73-8.34)$ & $8.54(0.71-8.28)^{*}$ \\
\hline Above 100,000 & 94.2 & 5.7 & $2.44(1.32-8.59)$ & $1.62(0.75-5.58)$ \\
\hline No answer & 67 & 33 & $0.46(0.71-1.87)$ & $1.33(0.47-2.27)$ \\
\hline \multicolumn{5}{|l|}{ Depression } \\
\hline Yes & 36 & 64 & $0.48(0.41-0.98)$ & $0.42(0.19-0.61)^{*}$ \\
\hline No & 89 & 11 & 1 & 1 \\
\hline \multicolumn{5}{|l|}{ Pill burden } \\
\hline 2 tablets & 91 & 9 & $3.67(1.08-10.03)$ & $13.01(2.71-62.43)^{*}$ \\
\hline 3 tablets & 89 & 11 & $3.83(1.43-15.22)$ & $12.34(2.77-52.52)^{*}$ \\
\hline 4 tablets & 82 & 18 & $3.32(0.49-8.87)$ & $6.73(2.55-27.83)$ \\
\hline 5 tablets and more & 77 & 23 & 1 & 1 \\
\hline \multicolumn{5}{|l|}{ Substance use } \\
\hline Used & 94.8 & 5.2 & $0.33(0.39-0.11)$ & $0.58(0.44-1.26)$ \\
\hline Not used & 89.2 & 10.8 & 1 & 1 \\
\hline \multicolumn{5}{|c|}{ Opportunistic infections (OIs) } \\
\hline Not encountered & 94 & 6 & $1.88(1.12-2.43)$ & $2.62(1.38-5.84)^{*}$ \\
\hline Encountered & 66 & 34 & 1 & 1 \\
\hline \multicolumn{5}{|l|}{ Disclosure status } \\
\hline No & 86.2 & 13.8 & $0.52(0.28-0.97)$ & $0.37(0.11-0.83)^{*}$ \\
\hline Yes & 84.3 & 15.7 & 1 & 1 \\
\hline \multicolumn{5}{|l|}{ Family support } \\
\hline Good & 85.4 & 14.6 & $1.66(1.32-2.75)$ & $2.79(1.34-4.48)^{*}$ \\
\hline Poor & 78.2 & 21.8 & 1 & 1 \\
\hline \multicolumn{5}{|c|}{ Adherence counselling } \\
\hline Yes & 89.3 & 10.7 & $3.13(1.12-6.35)$ & $2.44(0.28-1.03)$ \\
\hline No & 81 & 29 & 1 & 1 \\
\hline \multicolumn{5}{|c|}{ Well-skilled counsellor } \\
\hline Yes & 91.7 & 8.3 & $4.31(1.84-7.36)$ & $1.22(0.37-5.89)$ \\
\hline No & 78 & 22 & 1 & \\
\hline \multicolumn{5}{|c|}{ Satisfaction with counsellor } \\
\hline Satisfied & 93 & 7 & $1.24(1.03-4.02)$ & $1.31(0.29-4.10)$ \\
\hline Not satisfied & 84 & 16 & 1 & 1 \\
\hline
\end{tabular}

*Statistically significant $(p<0.05)$

Patients who were in the age of $35-44$ years old were 2.58 times $(\mathrm{AOR}=2.58 ; 95 \% \mathrm{CI}=1.14-4.09)$ more adherent than those in older age group ( $\geq 45$ years). Patients who earned an average income of between 18,000 and above per month were 8.54 times $(\mathrm{AOR}=8.54 ; 95 \% \mathrm{CI}=0.71-8.28)$ more likely adhered than those who earned less than 18,000. Patients who took two tablets (AOR $=13.01 ; 95 \% \mathrm{CI}=2.71-62.43)$ and three tablets $(\mathrm{AOR}=12.34 ; 95 \% \mathrm{CI}=2.77-52.52)$ per day were more adherent than those taking five and more tablets. Those who did not have history of opportunistic infection were 2.8 times $(\mathrm{AOR}=2.62 ; 95 \% \mathrm{CI}=1.38-5.84)$ more likely adhered than those who experienced opportunistic infection. The odds of adhering to ART was 2.79 times higher among those getting good family support $(\mathrm{AOR}=2.79 ; 95 \%$ $\mathrm{CI}=1.34-4.48$ ) than those who had poor family support. On the other hand, adherence was less ( $\mathrm{AOR}=0.37 ; 95 \%$ $\mathrm{CI}=0.11-0.83$ ) among patients who did not disclose their sero-status to any family member than their counterparts. It was also 0.42 times less likely to be adhered $(\mathrm{AOR}=0.42$; 95\% CI $=0.19-0.61$ ) among patients who did experience depression compared to those who did not.

Two hundred and twenty four $(82 \%)$ of the participants had taken $>95 \%$ of their prescribed ARV drugs for the past 7 days. Almost similar adherence rate was observed among males $(85.7 \%)$ and females $(87.5 \%)$. Higher adherence rate was observed in the age group of 35-44 years (92.8\%). However, adherence rate was not statistically associated with sex and age group.

Higher adherence rate $(91 \%)$ was observed among singles compared to married study participants $(82.3 \%)$. The respondents who had tertiary and higher degree education were more adhered (90.7\%) than those who had highest education at secondary $(80 \%)$ and primary $(81 \%)$ school level. However, there was no statistically significant 
association between the adherence rate and the marital status and the educational level of the study participants. Higher adherence rate, $88.3 \%$ and $97.6 \%$, was observed among employed study participants earning $<\$ 18,000$ and those earning between $\$ 18,000$ and above $\$ 100,000$ per month, respectively. However, there was no significant statistical association between the two variables

Adherence rate of $85.4 \%$ and $78.2 \%$ was reported among patients who had support from their family and those who had support from friends, governmental facilities, nongovernmental organizations, community-based organizations, and religious organizations respectively. Adherence rate of $86.2 \%$ and $84.3 \%$ was reported among patients who disclosed their positive sero-status to families and friends and who did not disclose their sero-status, respectively. About $94.8 \%$ and $89.2 \%$ adherence rates were reported by patients who were using active substances and who were not using active substances, respectively. There was significant impact on adherence rate of study participants by social support, disclosure of sero-status, and substance abuse as indicated.

More than half of the patients $171(63 \%)$ responded that they did experience adverse effects of ARV drugs in the previous one month prior to data collection date whereas 101 (37\%) of them reported they did not experience adverse effects. The common adverse effects were nausea and vomiting, skin rash and peripheral neuropathy.

\section{Discussion}

The findings of this study revealed and identified major obstacles peculiar to the study setting that affected clients' level of adherence to anti-retroviral therapy provided at Nnamdi Azikiwe University Teaching Hospital located at Nnewi, Nigeria in order to optimize strategies in the face of achieving the second and third 95 of the global target of UNAIDS $95-95-95$ by 2030. The level of adherence identified was $85 \%$. The reasons for skipping doses were forgetting to take the pills, being far from home, being busy, being extremely ill, pill burden, emotionally depression and running out of pill among others similar to findings obtained in other studies conducted in different contextual locations [19-23]. Factors associated with the ART adherence were age, income, pill burden, disclosure and depression status and family support [19-23].

Research Question 1: What are the socio-demographic factors that may influence adherence to ART? The level of adherence identified in this study indicated $85 \%$ lower than the current recommended $95 \%$ level of adherence. This is required to suppress viral replication and improve clinical signs $[24,30]$. This implies that much effort is still needed to push up the adherence to the recommended level [30] so as to achieve the overall goal of zero infection by 2030 . Comparatively, the adherence level identified in this study was found to be higher than that of other studies in different parts of the developing world such as Ethiopia [25], Yirgalem [26] and Jimma [27] as reported by Letta et al [30]. This may be due to the fact that many of the study participants have acquired experience in handling the various facets of the therapy and have devised measures to individually remind themselves of their regimens. Different contextual variations may also explain the difference observed, which may include the fact that the study setting is a student environment.

The level of adherence was significantly influenced by age as patients in age group of 35-44 years old were more likely to be adherent than the younger and older age groups. This is in support with a study conducted in Kenya that found ART adherence to increase with advanced age and decrease as the age goes beyond 60 years $[29,30]$. This might be deduced that the younger might fear sigma and discrimination from their peers and so miss medication.

In this study, the adherence rate of the respondents increased with an increase in their educational level as reported in some studies [27, 31], although, there was no significant association between the adherence rate and the educational level. Clients who are better educated understand more, have access to information and can make better informed decisions about their health. Similarly, verbal instructions equally given to patients who are illiterate seem effective as written instructions given to all patients [31, 32].

Research Question 2: What are the reasons for nonadherence to ART?

The major reasons for missing dose regimens were forgetting to take, being far from home, being busy, running out of pill, drug toxicity, too ill and fear of stigma which were similar to other studies conducted in Jimma [27], Nigeria [28], and Kenya [29]. The implication for this is that future interventions need to be structured to particular contextual settings [30], hence the need for this study to address these different aspects of care and treatment in HIV.

Patients who had an average income of $\$ 18,000$ and $\$ 100,000$ were more likely adhered than those who earned less than the minimum wage for workers in Nigeria $(<\$ 18,000)$. However, a study in Kenya found that employed patients who had higher monthly income were less adhered to treatments $[29,30]$. The explanation for this may be that lower income margins may subject the patient to difficult financial demands which may impact on the individual's psyche and thus level of adherence. It is also apparent that patients who have higher level income are usually those employed and engaged in business works which in one way can subject them to busy schedules and staying away from home at the time of taking the routine dose [30]. However, in this study, the income of the participants did not significantly affect their adherence. This may be due to the fact that ARV drugs have been made free of charge in Nigeria since 2006 through the interventions of international funders like Global Fund and US President's Emergency Plan for AIDS Relief (PEPFAR). Low economic status was not a predictor of adherence for patients with fully subsidized therapy [26, 27, 31]. Generally studies have shown adherence level of clients are more likely to increase on free basis of treatment as illustrated by a study conducted on Myanmar migrants living in Thailand [33]. 
Depressed patients were about 0.42 times less likely adherent than those non-depressed as revealed by this study. Other findings are also in support of the finding [25, 27, 30]. This might be that those depressed patients may usually feel dejected and demoralized as they may feel their whole world has gone awry. This finding implies that there is a need to design and integrate psychological evaluation into every form of counselling [30] provided to clients in ART clinical settings since it has been indicated that majority of deaths from HIV/AIDS can be attributed to self-rejection and a desire to end life resulting in low adherence.

\section{Conclusion}

The ART level of adherence in this study was found to be $85 \%$ lower than the optimal $95 \%$ adherence level. It was revealed that the patient age, monthly income, pill burden, disclosure status and family support were the factors responsible for the sub-optimal level of ART adherence in the study area. Upon the premise of the study findings, the researchers recommend a more inclusive approach to treatment and care of HIV clients. Government and various stakeholders in HIV intervention should be at the center of the know in strategizing and developing remedies that work best in different contextual settings. Disclosure of status should be made a core requirement for increased ART adherence. Improved education and counselling, training on self-management skills for medication administration and reminders are also advocated. Efforts at all levels of care and community mobilization ought to be prioritized for optimal adherence and achievement of 95-95-95 target elimination of HIV by 2030. A qualitative approach to the study is hence advocated for more insightful analyses of these factors.

\section{Authors' Contributions}

This work was carried out in collaboration between all authors. Author John Ndie designed and supervised the study. Authors Mary Nnenna Ibezim and Emeka Victor Ifemenam performed the data collection process. Authors Mary Nnenna Ibezim, Uchechukwu Chibuzo Ogbodo, Ogonnaya Kanu-Oji, Michael Olugbamila Dada, Emeka Victor Ifemenam managed the analyses of the study and the literature searches. Authors Uchechukwu Chibuzo Ogbodo and Ndubuisi Oji wrote the protocol while Uchehukwu Chibuzo Ogbodo wrote the first draft of the manuscript. All authors read and approved the final manuscript.

\section{Disclosure of Potential Conflict of Interest}

The authors declare and hereby disclose that no conflict of interest exist.

\section{Acknowledgements}

The authors would like to thank the editors for submitting their insightful research for publication and the reviewers for their important input and critiques to improve the manuscripts.

\section{References}

[1] UNAIDS (2008). 2008 Report on the global. HIV/AIDS epidemic 2008. Geneva Switzerland: UNAIDS, 2008.

[2] National Agency for the control of AIDS (2011): Antiretroviral therapy (ART) in Nigeria. Fact sheet 2011.

[3] Federal Ministry of Health (2010): 2010 National HIV seroprevalence Sentinel Survey. 2010, Abuja: Federal Ministry of Health.

[4] Rao, D., Kekwaletswe, T. C., Hosek, S., Martinez, J. and Rodriguez, F. (2007). Stigma and social barriers to medication adherence with urban youth living with HIV. AIDS Care. 19 (1): 28-33.

[5] Tapper, M., Flexner, C., Eron, J. J. and Molina, J. (2004). Simplifying antiretroviral therapy. AIDS Care. 14 (7): 355367.

[6] Remien, R. H., Bastos, F. I., Terto, Jnr V., Raxach, J. C., Pinto, R. M., Parker, R. G., et al (2007). Adherence to antiretroviral therapy in a context of universal access, in Rio de Janeiro, Brazil. AIDS Care. 19 (6): 740-748.

[7] Weiser, S., Bangsberg, D., Thior, I., Gilbert, P., Makhema, J., Kebaabetswe, P. et al. (2003). Barriers to antiretroviral adherence for patients living with HIV infection and AIDS in Botswana. J Acquir Immune Defic Syndr. 1 (34): 281-8.

[8] Weiss, L., French, T., Finkelstein, R., Waters, M., Mukherjee, R. B. A. (2003). HIV-related knowledge and adherence to HAART. AIDS Care. 15 (5): 673-679.

[9] Nilsson-Schönnesson, L., Diamond, P. M., Ross, M. W., Williams, M. and Bratt, G. (2006). Baseline predictors of three types of antiretroviral therapy (ART) adherence: a 2-year follow-up. AIDS Care 18 (3): 246-253.

[10] Reynolds, N. R., Testa, M., Marc, L., Chesney, M., Neidig, J., Smith, S., et al (2004). Factors influencing medication adherence beliefs and self-efficacy in persons naïve to antiretroviral therapy: A multi-center, cross-sectional study. AIDS Behaviour. 8 (2): 141-150.

[11] Mohammed, M. D. (2004). Adherence to antiretroviral drugs in North-Central zone of Nigeria. East Cent Afr J Pharm Sci. 7 (3): $52-55$.

[12] Iliyasu, I., Kabir, M., Abubakar, I., Babashani, M. and Zubair, Z. (2005). Compliance to antiretroviral therapy among AIDS patients in Amino Kano Teaching Hospital, Kano. Niger $J$ Med. 14 (3): 290-294.

[13] Monjok, E., Smesny, A., Okokon, I. B., Mgbere, O. and Essien, J. (2010). Adherence to antiretroviral therapy in Nigeria: An overview of research studies and implications for policy and practice. HIV/AIDS - Res Palliat Care 2: 69-76.

[14] Unge C, Södergård, B., Marrone, G. et al (2010). "Long-Term Adherence to Antiretroviral Treatment and Program Drop-Out in a High-Risk Urban Setting in Sub-Saharan Africa: A Prospective Cohort Study," PLOS ONE, vol. 5, no. 10, p. e13613. 
[15] Scanlon, M. L. and Vreeman, R. C. (2013). Current strategies for improving access and adherence to antiretroviral therapies in resource-limited settings $H I V A I D S$, vol. 5, pp. 1-17.

[16] Bangsberg, D. R., Hecht, F. M., Charlebois, E. D. et al. (2000). Adherence to protease inhibitors, HIV-1 viral load, and development of drug resistance in an indigent population, AIDS, 14 (4): 357-366.

[17] Barclay, T. R., Hinkin, C. H., Castellon, S. A., Mason, K. I., Reinhard, M. J., Marion, S. D., Levine, A. J. and Durvasula, R. S. (2007). Age-associated predictors of medication adherence in HIV-positive adults: health beliefs, self-efficacy and neurocognitive status. Health Psychology 26 (1): 40-9.

[18] Bova, C. A., Fennie, K. P., Knafl, G. J., Dieckhaus, K. D., Watrous, E. and Williams, A. B. (2005). Use of electronic monitoring devices to measure antiretroviral adherence: practical considerations. AIDS Behav. 9 (1): 103-10.

[19] Chirambo, L., Valeta, M., Banda Kamanga, T. M. and Nyondo-Mipando, A. L. (2019). Factors influencing adherence to antiretroviral treatment among adults accessing care from private health facilities in Malawi. BMC Public Health 19: 1382.

[20] Molla, A. A., Gelagay, A. A., Mekonnen, H. S. and Teshome, D. F. (2018). Adherence to antiretroviral therapy and associated factors among HIV positive adults attending care and treatment in University of Gondar Referral Hospital, Northwest Ethiopia. BMC Infect Dis 18: 266.

[21] Negesa L, Demeke E. and Mekonnin W. (2017). Adherence to Antiretroviral Therapy and Factors affecting among People Living with HIV/AIDS and Taking Antiretroviral Therapy, Dire Dawa Town, Eastern Ethiopia. J Infec Dis Treat. 3: 1.

[22] Basti, B. D., Mahesh, V., Bant, D. D. and Bathija, G. V. (2017). Factors affecting antiretroviral treatment adherence among people living with human immunodeficiency virus/acquired immunodeficiency syndrome: A prospective study. J Family Med Prim Care. 6 (3): 482-486.

[23] Abera, A., Fenti, B., Tesfaye, T. and Balcha, F. (2015). Factors Influencing Adherence to Antiretroviral Therapy among People Living With HIV/AIDS at ART Clinic in Jimma
University Teaching Hospital, Southwest Ethiopia. J Pharma Reports 1: 101-106.

[24] WHO (2010). Scaling up priority HIV/AIDS interventions in the health sector, Progress Report, Towards universal access.

[25] Tefera, G. (2011). Personal factors influencing patients ART adherence in Addis Ababa, Ethiopia. J Assoc Nurses AIDS Care. 24 (6): 530-538.

[26] Markos, E., Worku, A. and Davey, G. (2008). Adherence to ART in PLWHA at Yirgalem hospital, South Ethiopia. The Ethiopian Journal of Health Development, 22 (2): 174-179.

[27] Amberbir, A., Woldemichael, K., Getachew, S., Girma, B. and Deribe, K. (2008). Predictors of adherence to antiretroviral therapy among HIV-infected persons: a prospective study in Southwest Ethiopia. BMC Public Health, vol. 8, article 265.

[28] Bello, S. I. (2011). HIV/AIDS patients' adherence to ART in Sobi specialist hospital, Nigeria. $J A d v$ Sci Res. 2 (3): 52-7.

[29] Anthony, N. (2011). Factors that influence non-adherence to antiretroviral therapy among HIV and AIDS patients in central province, Kenya.

[30] Letta, S., Demissie, A., Oljira, L. and Dessie, Y. (2015). Factors associated with adherence to Antiretroviral Therapy (ART) among adult people living with HIV and attending their clinical care, Eastern Ethiopia. BMC Int Health Hum Rights 15,33 (2015).

[31] Cauldbeck, M. B., O'Connor, C. and O'Connor, M. B. (2009). Adherence to anti-retroviral therapy among HIV patients in Bangalore, India. AIDS Research and Therapy vol. 6, article 7.

[32] Mikitu, H., Abdosh, T. and Teklemariam, Z. (2013). Factors affecting Adherence to Antiretroviral Treatment in Harari National Regional State, Eastern Ethiopia. ISRN AIDS Vol 2013: 1-7.

[33] Han, N., Phoolcharoen, W. and Perngparn, U. (2009). Antiretroviral drug taking in HIV positive among Myanmar migrants in central area of Thailand. Journal of Health Research, vol. 23, supplement, pp. 33-36. 